\title{
Knowing More from Less: How the Information Environment Increases Knowledge of Party Positions
}

\author{
SUSAN BANDUCCI, HEIKO GIEBLER AND SYLVIA KRITZINGER*
}

\begin{abstract}
Access to information is a hallmark of democracy, and democracy demands an informed citizenry. Knowledge of party positions is necessary for voters so that electoral choices reflect preferences, allowing voters to hold elected officials accountable for policy performance. Whereas most vote choice models assume that parties perfectly transmit positions, citizens in fact obtain political information via the news media, and this news coverage can be biased in terms of salience - which leads to asymmetric information. This study examines how information asymmetries in news coverage of parties influence knowledge about political party positions. It finds that the availability of information in the news media about a party increases knowledge about its position, and that party information in non-quality news reduces the knowledge gap more than information in quality news.
\end{abstract}

A necessary condition for democracy to function properly is that citizens make informed electoral decisions. If voters are to respond to a party's policy performance, knowledge of (and an understanding about) the parties' policy positions is of primary importance. In particular, information plays a crucial role for both voters and parties in spatial voting models in which to secure, increase or even maximize their vote shares, parties are keen to take up favourable policy positions on whatever dimension is relevant in the specific election. At the same time, voters' identification of the party yielding the highest utility regarding their vote choice depends on knowledge about parties' positions. ${ }^{1}$

There is a degree of uncertainty in each election, as voters will not know precisely the effect that a vote for a particular party or candidate will have on their welfare. Greater awareness of the positions of parties will, however, reduce uncertainty about the consequences of electing a particular party. ${ }^{2}$ Hence, information has a twofold effect on voters. First, a voter's own position is better informed and is more likely to be consistent with other issue orientations. Secondly, voters are better able to identify party positions correctly - the information effect we focus on in this article - and vote more consistently with their own preferences.

In models of vote choice, the information chain between parties and voters has mostly been analysed directly: parties offer information on their policy positions to the electorate, and based on this information a voter will then choose the party that is most proximate to her position

* University of Exeter (email: s.a.banducci@exeter.ac.uk); WZB Berlin Social Science Center (email: heiko. giebler@wzb.eu); University of Vienna (email: sylvia.kritzinger@univie.ac.at). Support for this research was provided by the Economic and Social Research Council (ES/K004395/1) and the Austrian Science Fund (S10902-G11). A previous version was presented at the ECPR Joint Sessions in Mainz 2013. We are grateful to the participants of the workshop as well as the three anonymous referees for helpful comments. Data replication sets are available at http://dataverse.harvard.edu/dataverse/BJPolS, and online appendices are available at http:// dx.doi.org/doi:10.1017/S0007123415000204.

${ }^{1}$ In most of the approaches, utility is not defined as a true utility but as a subjective utility. Information affects these two types of utilities differently. While true utility depends on the degree of true information, subjective utility does not depend on true information.

${ }^{2}$ Downs 1957 . The same is true for valence issues. Here, information does not focus on party positions, but voters need information on issue ownership and salience in the party programme. 
(proximity) or the one on her side of the status quo (directional). ${ }^{3}$ Such an approach relies on various assumptions, such as that political parties 'communicate their messages' via party manifestos ${ }^{4}$ or that there is no news media bias in reporting on parties. If, however, the latter is not the case, the information chain is not a constant but a media-specific one. The news media do act strategically, either to increase their audience share or represent a particular political position, and thus can alter the type and amount of information. ${ }^{5}$ That party placement is endogenous to the media/information environment would have serious implications for any analysis that uses issue distance to predict vote choice: issue distance is then not simply a function of preferences but also of the amount and quality of information available about a party.

In this article we therefore examine how information exposure and the availability of information influence voters' knowledge about parties' policy positions. We argue that news media play an important role in translating the nature of party competition for voters, and that the amount of information on parties in news stories impacts voters' knowledge about political parties. In other words, as most citizens' experience of the political world is mediated, news outlets play an important role in translating the electoral supply of party alternatives to citizens, and where news media cues are stronger, citizens will be more knowledgeable about party positions - in the sense that they know better where parties stand on an issue. In environments that lack such information voters are more likely to remain uncertain about the policy positions of parties. Thus we examine a respondent's ability to determine a party's position on a particular issue based on the amount of information she has received about that particular party.

We analyse the impact of news media information imbalance on citizens' information level by examining their ability to place parties on the issue dimension of European integration. Our method of analysis links news media content indicators of the information environment to the individual level, which includes - amongst others - measures of individual perceptions of party positions. We use a within-subject design in which we compare for the same individual how variations in news information about all parties influence knowledge levels.

We proceed as follows: we first provide a framework for understanding the impact of the news information environment on political knowledge. Our next step is to clarify our analysis, presenting the within-subject design in detail and developing a measure of knowledge about party placements. Finally, our results demonstrate that the news information context has a mediating effect on political party knowledge and find that, as suggested by past research, this is partly conditioned by the quality of news outlets. These effects are small, but nonetheless have important implications for the interpretation of vote choice models if we consider that media effects can have a cumulative impact. ${ }^{6}$

\footnotetext{
${ }^{3}$ Here we simplify the debate over the directional and proximity models of vote choice, but see, for example, a number of studies comparing directional and proximity models: Westholm (1997), Macdonald, Rabinowitz and Listhaug (1998), and Rabinowitz and Macdonald (1989). Our argument is not that one model provides a better representation of a voter's calculus, but rather that each model relies on some knowledge about party positions. The empirical analysis that follows from each of the models uses some measure of distance between a respondent's issue preference and his or her placement of the party.

${ }^{4}$ It also includes the assumption that parties are interested in conveying their exact policy positions. However, parties might be interested in being ambiguous about their positions or not mentioning them at all (e.g., Rovny 2012). Similarly, we know the news media may not perfectly reflect policy positions and may frame issues to emphasize particular aspects. We acknowledge these possibilities, but cannot in the context of this article model 'strategic ambiguity' (Shepsle 1972), and therefore assume that the more information via the news media is available the easier it is to identify a party's policy position.

5 Chan and Suen 2009; Mendelsohn and Cutler 2000; Swanson and Mancini 1996; Zaller 1999.

6 Lecheler and de Vreese 2013.
} 
Politically informed voters are more likely to participate in politics and have a better overview of politics and policies. ${ }^{7}$ For spatial voting to work effectively, voters also need to be informed about the policy positions of the various parties running in the electoral competition. Voters with more information will be more likely to be certain about the different parties' policy positions; they will also be more likely to place parties accurately on different issue dimensions and express an informed vote. ${ }^{8}$ On the other hand, citizens with "more uncertain information are less likely to be able to base decisions on that information'. ' Information will be particularly relevant when voters have to judge the position of more than two actors (for example, political parties and candidates).

Imperfect and incomplete information can manifest in different ways. First, a voter's ordering of political actors based on electoral utility represents only a subsample of all available parties because a voter cannot calculate a utility if information on a party is missing. Citizens are then either forced to limit their options to this restricted choice set or rely on other cues and heuristics like party identification, candidate images or actor's positions on other issues. This is not problematic per se, but due to the different origins and quality of information for different choice options, the decision-making process differs from a situation in which a citizen has information on all actors.

Secondly, a lack of information can also result in the misplacement of actors regarding their policy positions. For instance, Alvarez and Franklin show that a large proportion of respondents was not certain about the position of their own senator on particular policy positions, and that they were in general uncertain about the policy positions of the various political parties. ${ }^{10}$ In these situations the working of the responsible party model is endangered: citizens' policy positions communicated by vote choice will not result in correspondent policy decisions taken by the executive or legislative because the position of political actors differs from the perceived position of the voters that is used to determine the utility of different choice options.

Based on these severe consequences of information asymmetry across the set of party alternatives, we are overall interested in examining the mechanisms related to how voters become knowledgeable about party policy positions, but first and foremost, in exploring which role the media play in conveying information on party policy positions during a campaign. Gelman and King write that 'information about candidates' position on issues is [...] the most important role of the media' ${ }^{11}$ and we aim to examine whether (and under what conditions) the media can inform citizens about the policy positions of parties. Electoral campaigns are the ideal moments for information acquisition as elections are a priority for both parties and news media. ${ }^{12}$ Based on these theoretical considerations, we test the following hypothesis:

HYPOTHESIS 1: As information on party positions becomes more available, citizens will be better able to verify the accurate position of parties on issues.

7 Delli Carpini and Keeter 1996.

${ }^{8}$ Lenz 2012. In his recent book, Lenz raises doubts about whether individuals vote based on policy positions. While these are worrying results for democracy per se, he however shows that information can induce changes in voters' evaluations of party positions: either by adapting their positions to the ones of the most preferred party, or though to a lesser extent - by changing their party support.

9 Alvarez and Franklin 1994, 686. Uncertainty is defined as the absence of information about relevant variables.

${ }^{10}$ Alvarez and Franklin 1994.

11 Gelman and King 1993, 449.

12 Ansolabehere and Iyengar 1995; Gelman and King 1993. 
While there may be some spill over of news information from personal discussions and social networks, we would not expect those who are not exposed to news media to be directly influenced by content. ${ }^{13}$ In other words, the environment may be rich in information, but it will have little impact on citizens unless they consume it via a media outlet. Therefore, we test a second hypothesis:

HYPOTHESIS 2: As information on party positions becomes more available, citizens who consume news on a daily basis will be better able to verify the accurate position of parties on issues than those who do not consume news content regularly.

There are reasons to expect that it is not simply the volume of information that matters but also the quality. In the growing body of comparative media effects research, one conclusion is that the quality of the news outlet - such as broadsheets and public service broadcaster (PSB) in comparison to tabloids or commercial broadcast - influences how informed voters are. ${ }^{14}$ Citizens who obtain their information via quality news outlets might have a better understanding of the political space, as they are more likely exposed to policy-relevant news and party stances connected to it. ${ }^{15}$ However, there is growing evidence that there are also knowledge gains for those who seek out information in low-quality sources, such as tabloids. Soft news with clear and easily accessible messages - and in particular, candidate appearances in less serious news formats can serve to increase knowledge about candidates. ${ }^{16}$ However, others have argued that soft news has a limited effect on political knowledge. ${ }^{17}$ Therefore, our third hypothesis looks at the type of information, distinguishing between high- and low-quality information channels. We refrain from postulating a directional hypothesis due to contradicting evidence in other studies.

HYPOTHESIS 3: The type of outlet in which information on political parties is retrieved affects knowledge of parties' policy positions.

\section{Analysing Media Effects by Linking News Content to Individuals}

Because we want to understand how asymmetric information about parties in the information environment influences knowledge of political parties, we test whether watching or reading a particular news story alters what citizens know about political parties. Most studies that have sought to examine the impact of information levels on knowledge have tended to focus on how exposure to news, rather than the news content itself, has influenced political knowledge. ${ }^{18}$ However, media are not neutral actors. They might privilege an issue or an actor relative to others, and report more about it. Therefore we examine both the individuals' exposure to the news media and its content in order to capture potential different weights that news media assign to certain actors and their positions. Asymmetric information transmission is therefore inherent in the individuals' news consumption.

13 Mendelsohn 1996.

14 Aarts and Semetko 2003; Curran et al. 2009; Dimock and Popkin 1997; Soroka et al. 2013.

15 Aalberg, van Aelst, and Curran 2010; de Vreese et al. 2006; Peter, Lauf, and Semetko 2004; Schuck et al. 2011.

16 For a review of the concept of 'soft news', see Reinemann et al. (2011) and Baum (2003). For evidence of the effects of soft news on evaluations of candidates, see Brewer and Cao (2006).

17 Prior 2003.

18 Studies focusing on media exposure and its impact on knowledge include Delli Carpini, Lomax and Jacobs (2004), Lenz (2012), and Aalberg, van Aelst, and Curran (2010). Studies linking news media content to individual levels of political knowledge include Jerit, Barabas, and Bolsen (2006) and Barabas and Jerit (2009). 
Aside from ignoring the actual content of news, another issue in these studies is the problem of self-selection. Most research includes self-reports of exposure to news media and uses this to predict knowledge. However, we remain unsure about the causal direction when a relationship is uncovered: ${ }^{19}$ Are more knowledgeable citizens more likely to seek out information than the less knowledgeable, or do news consumers become more knowledgeable from being exposed to news stories?

Within political communications research, it is understood that the only way to truly rule out the problem of self-selection and a spurious relationship is to employ experiments. However, we know that experimental settings do not accurately reflect how citizens encounter or engage with news media content in the real world, and scholars have started to question the size of effects detected in experiments and whether some types of experiments can rule out selection problems. $^{20}$

Because we are interested in how variations in the news environment affect knowledge, our approach more closely follows that employed by Barabas and Jerit and Jerit, Barabas and Bolson when linking news media content to knowledge measures. ${ }^{21}$ Barabas and Jerit compare how variations in news information on a particular topic influence knowledge on the same topic for the same individual. This within-subject design holds constant the individual level variables that might be endogenous. In this approach, there is no control group; all experimental subjects (individuals) are exposed to each level of treatment of the treatment variable. Each individual is compared against her baseline, allowing the researcher to control for unobserved individual characteristics. By asking the same respondent to place multiple parties on a dimensional policy scale, we can assess, for each individual, how different levels of information about each party influence the placement of each party. For instance, for a single individual we can see if greater levels of information about Party A compared to Party B lead to a more accurate placement of Party A. If the level of information about a party produces differences in a single individual's ability to place a party, we are able to draw a much more robust conclusion about the influence of news information. ${ }^{22}$ Hence, the outcome is party placement and the treatment is the amount of information about the party. Our design lets us determine the impact of varying party-specific information in addition to constant effects.

If the news media coverage does influence knowledge of party positions, what effect size would we expect? And given our sample size, would we expect this effect size to be statistically significant? Generally, as suggested by Zaller, traditional election study sample sizes are not

19 There are some exceptions to this general trend in the existing studies that both employ techniques such as sample matching and link media content to measures of public affairs knowledge. Sample matching is an attempt to create equivalent treatment and control groups to account for unobserved (selection) factors that may be influencing the outcome variable. Soroka et al. (2013) created matched groups that differ by self-reported viewing of PSB, which means the results should be less affected by endogeneity. Their conclusion is that those watching PSB are more knowledgeable about public affairs. That the results with matching are no different than non-matched results suggests that either the impact of selection is exaggerated or that the matching does not completely resolve the issues. Soroka et al. admit the quality of the resulting estimates is dependent on the quality of the statistical modelling for the matching. Because this approach does not integrate measures of news content, we also must assume that the news content respondents are exposed to varies between the treatment (public service viewing) and control groups.

${ }^{20}$ Sekhon and Titiunik 2012.

21 Barabas and Jerit 2009; Jerit, Barabas, and Bolsen 2006.

${ }^{22}$ For example, the effect of political interest is measured on the level of the individual respondent, and its effect on the ability to place a party correctly is constant for all parties a respondent has placed: it is thus controlled for within the subject's responses on party placements. It helps reduce the problem of self-selection because we are able to hold unobserved factors constant for each individual, and examine changes for a single individual at the same time. 
powerful enough to detect media exposure effects that may be small. ${ }^{23}$ And media effect sizes, particularly those based on survey data, do tend to be small. Research on the media effects on antisocial behaviour demonstrates that effect sizes in laboratory experiments tend to be larger than those in surveys. ${ }^{24}$ Hence, we expect that our media effects measured in observational data would even be even smaller. However, taking into consideration that media effects might be cumulative, even these small effects can be of relevance in the long run.

\section{DATA AND METHODS}

European Parliament (EP) elections are considered less important than national elections by both parties, in their efforts to communicate their policy positions, and the news media that dedicate less time and coverage to these events. ${ }^{25}$ This lack of attention is likely to lead to an information asymmetry amongst voters. ${ }^{26}$ While the relevance of the European issue has increased over time, citizens still clearly consider the left-right dimension to be more important; therefore it is less likely to represent a general orientation to political preferences or a heuristic for voters. ${ }^{27}$ Thus information provided by news media might be particularly important to communicate parties' policy positions on the issue of European integration. As such, it is an ideal case to analyse whether the media content we are interested in (news about Europe), is what voters are responding to.

In order to test our hypotheses, we rely on data from the European Election Study 2009 (PIREDEU). ${ }^{28}$ The survey carried out immediately after the election in June 2009 provides the data on citizens' placement of parties. Respondents were asked to place all relevant parties in their country regarding their positions towards the issue of EU integration on an eleven-point scale. It also includes all measures necessary to establish a fine-grained link with the media content data for each respondent. For each of the coded news media, respondents are asked whether they read/watch it, and if so, how many times a week. Furthermore, it provides relevant individual characteristic variables. Data on the media content analysis based on campaign news coverage leading up to the EP election is used to provide a direct measure of the amount of electorally relevant information about each political party. Over a three-week period, the content analysis was carried out on a sample of national news media coverage in all twenty-seven EU member states (comprised of broadsheets, tabloids, public and commercial broadcasts). ${ }^{29}$ The overall television sample consists of fifty-eight TV networks and the overall newspaper sample includes eighty-four different newspapers. ${ }^{30}$ Finally, data on parties' positions on Europe is captured from the Euromanifesto database and the European Election Candidate Study.

${ }^{23}$ Zaller 2002.

${ }^{24}$ Paik and Comstock 1994; Preiss et al. 2007. As an example of the difference in effect size for lab- and survey-based studies, in a meta-analysis of 217 studies examining the media effects on violent behaviour, Paik and Comstock find that lab experiments had an average effect size of 0.40 ( $\mathrm{Z}_{\text {Fisher }}$ score) whereas survey-based studies had an average effect size of 0.19 . In a summary of meta-analyses carried out across media effects research, Preiss and others conclude that laboratory settings with their controlled environment yield stronger effects but that media effects research in general yields small effect sizes $(r \leq 0.2)$.

${ }^{25}$ de Vreese et al. 2006; van der Eijk and Franklin 2004.

${ }^{26}$ Koch 2008.

27 de Vries 2007.

${ }^{28}$ Data collection for the candidate survey, post-election survey, media content analysis and Euromanifestos project was carried out under the auspices of 'Providing an Infrastructure for Research on Electoral Democracy in the European Union' (PIREDEU) (Braun, Mikhaylov, and Schmitt 2010; Giebler, Haus, and Weßels 2010; Schuck et al. 2010; van Egmond et al. 2013; Weßels 2011).

${ }^{29}$ We focus on national television and newspapers because these media are consistently listed as the most important sources of information about the EU for citizens in Europe (Eurobarometer 54-62).

${ }^{30}$ The list of outlets, as well as more information on the coding, can be found in Schuck et al. (2011). 


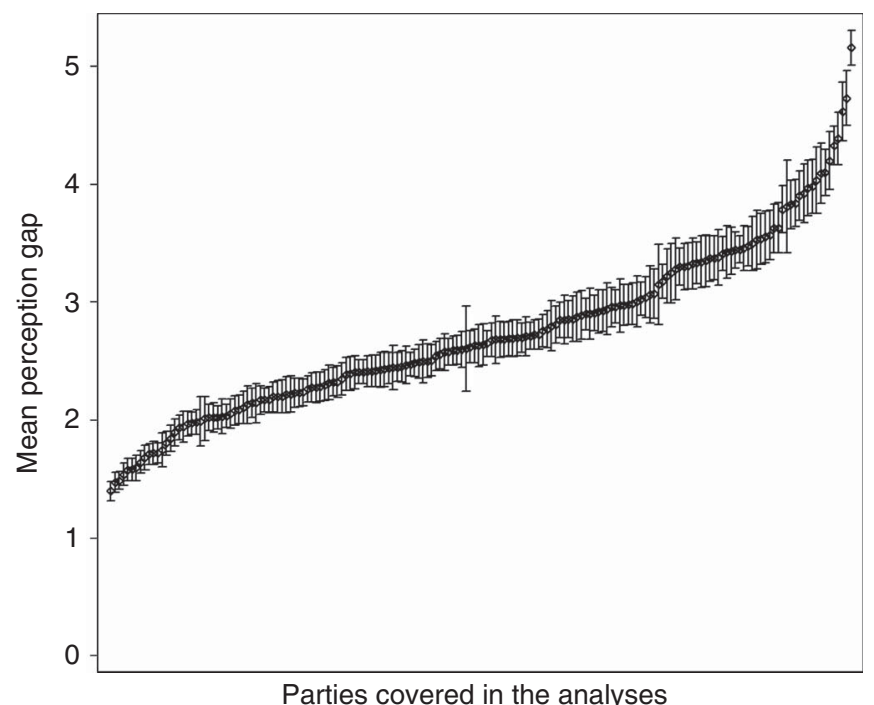

Fig. 1. Mean perception gap for each party (with $95 \%$ confidence intervals)

Note: the figure shows the average gap between the respondents' placement of the party and the party's verified position based on our estimation for each party (parties are sorted by the average size of the gap between their verified position and the respondent's perceived placement of the party).

Turning to the measures used in our model, we start with our dependent variable (Perception Gap): the gap between what we refer to as the empirically verified party position and a respondent's perceived party positions on the issue of European integration. Respondents are more knowledgeable about a party the closer they are to estimating its verified position.

There is no consensus in the literature on how to obtain empirically verified party positions. Some studies use the average perceived party position calculated on the basis of mass surveys as a proxy for the verified position, while others work with expert judgements or data from candidate surveys and electoral party manifestos. Each approach suffers from drawbacks that might jeopardize the validity of our empirical results. ${ }^{31}$ For our measurement of party positions we use the information provided by parties, namely from the candidate survey and the manifesto study, for a multiple imputation procedure to generate verified party positions for a large set of parties competing in the 2009 EP elections, which results in an efficient measure of party positions. ${ }^{32}$

Figure 1 provides information on our dependent variable, Perception Gap. It shows the mean perception gap for each party covered in our analyses. In general, respondents are not able to accurately place parties on the EU issue dimension. The smallest average perception gap for a

${ }^{31}$ For a discussion on party positions, its various measurements and drawbacks see the supplementary material.

${ }^{32}$ For detailed information on the multiple imputation procedure, see the supplementary material. We use 'empirically verified party position' to designate our estimate of where the political party is positioned in the issue space. Our goal in the article is not to construct a 'true' measure of party placement or to test a new measure of party placement on European integration such as in the work of the Chapel Hill Expert survey (Bakker et al. 2015), but rather to examine the effects of the availability of information in the news about a party on voters' knowledge about the party's placement on issues. However, to carry out the tests, we need to obtain a reliable estimate to measure the gap between the respondent's perceived position and an estimate of the party's positions on an issue (European integration in this case). We refer to this estimate of the party's position, interchangeably, as the 'empirically verified' or 'verified' party position. We discuss our measure in detail in the supplementary material and provide robustness checks across a number of other measures. 


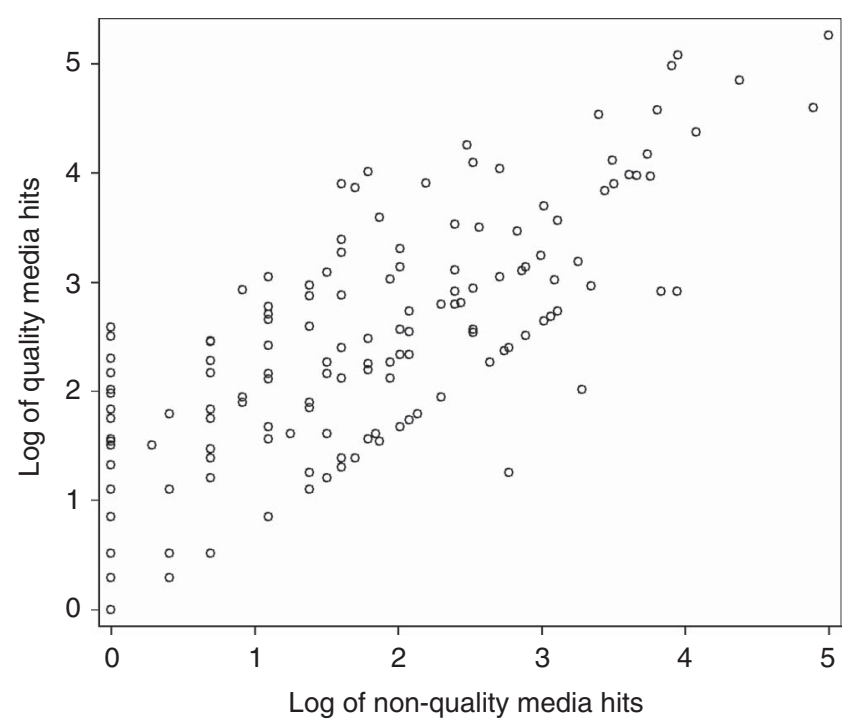

Fig. 2. Relationship between media hits in quality and non-quality news sources for each party Note: the figure displays the log value of the count of times a political party (a party actor or in its entirety) appeared in all news stories about the EU.

party exceeds one point on the scale, while for some parties the gap is almost five points. ${ }^{33}$ That we find respondents who do not accurately perceive party positions is not surprising and fits well with the research showing that the EU dimension is less important, even in EP elections, than the left-right dimension. Given these large perception gaps, it is important to explore the factors that reduce the gap, particularly the influence of news media information.

To measure the party-specific information available in the news environments, we focus on news stories from our media content analysis that mention the EU. Within each story we code the party associated with political actors that appear in the story. Our measure of the information available about a party in news stories is the total number of media mentions or 'hits' (excluding mentions of government ministers) that a party received in all news stories that mention the EU. Our measure of 'media hits' is intended to capture the amount of party information available that should assist voters in becoming knowledgeable about party positions on European integration. The more times a party or members of the party are mentioned in the news story about the EU, the more information about the party's position on the EU should be available in the story.

This measure of media hits varies across parties in a country and news outlets such that we have media hits on parties in television broadcasts and newspapers across all member states. To capture decreasing returns of additional information on knowledge, in all models we use the log of media hits. To grasp the potential differences in information transmission based on the type of outlet, we calculate the media hits in high- and low-quality outlets by counting media hits by party in the different types of outlets. We provide a descriptive account of the number of media hits in Figure 2.

Clearly, there is a positive relationship between the two measures. Parties featuring prominently in one type of outlet are also more frequently featured in the other type. Moreover,

33 To verify that these substantial gaps are not caused by our measurement approach, we also calculated the perception gap as the absolute difference between the perceived position and the mean perceived position of a party. The gaps are of similar size, indicating that respondents are indeed not very well informed about parties' positions on EU issues. More information can be found in the supplementary material. 
the number of media hits varies substantially between parties, indicating that the amount of available information on different parties is far from universally equal and will vary considerably across an individual - which is a benefit of our within-subject design.

Our measure of a respondent's media exposure is constructed from the voter survey: each respondent was asked to indicate the number of days she used the newspapers and TV news broadcasts coded in the media analysis. From this set of questions we constructed a measure of the days of media use overall, which is the maximum number of days consuming news in any of the outlets. ${ }^{34}$ There are two advantages to our measure. First, we capture the probability of being exposed to the content we have coded. Secondly, asking respondents about specific outlets (for example, how many days a week spent reading The Guardian) minimizes over-reporting. ${ }^{35}$ When modelling the impact of high- and low-quality news information, we create two separate exposure variables that capture exposure to the separate categories of news content. In the model, we link the amount of information available about a party and an individual's level of exposure by interacting media hits with the maximum number of days spent reading or watching the outlets used to calculate the number of media hits.

Because a respondent may use an outlet other than the ones coded in the media analysis, we also include an exposure measure to news outlets other than those coded. The latter cannot be measured in days of media consumption because the data are not available in the voter survey. Here, we rely on a binary measure that identifies respondents who had exposure to uncoded news outlets and those who had not. In the analytical models focusing on either quality or non-quality news, this variable refers to whether a respondent is consuming non-quality news in the model measuring the impact of quality news - or whether a respondent is consuming quality news - in the model measuring the impact of non-quality news.

We also include a set of control variables at the party, individual (subject specific) and country levels to ensure that any evidence of media effects is not a mere consequence of an omitted variable bias. ${ }^{36}$ On the party level, we control for incumbency, as the positions of incumbent parties might be perceived as more certain. At the individual level, we include voters' political interest $^{37}$ and level of EU identity, and take into account how likely a respondent says she is ever to vote for a party (propensity to vote): those who are likely to vote for a party might be more likely to know where it stands on the issue of Europe. Additionally, we include a measure that identifies respondents with problematic answering patterns such as assigning the same position to all parties. Finally, on the country level, we include a measure of programmatic diversity and the effective number of electoral parties. The coding for all variables is given in Table $1 .{ }^{38}$

\section{RESULTS}

\section{Media Effects on Party Placements Knowledge}

Following the necessities of a within-subject design and acknowledging the potential importance of contextual factors, we set up a three-level data structure. To perform our

34 The outlets coded in the media content are given in Schuck et al. (2011).

35 Barabas and Jerit 2009; Prior 2009; Stevens 2008.

36 Fortunately, the model is not sensitive to the range of control variables we include in various robustness checks at the individual, party and country levels.

37 The results are not sensitive to the inclusion of education as a substitute for cognitive abilities or the inclusion of both interest and education. However, both indicators are highly correlated in the data; thus to simplify the model we have only included political interest.

38 Additional information on our control variables can be found in the supplementary material. 
TABLE 1 Operationalization of Variables

\begin{tabular}{|c|c|}
\hline Name & Description \\
\hline Perception Gap & $\begin{array}{l}\text { Absolute distance between respondent's party placement and verified party } \\
\text { position on European integration scale }(0-11)\end{array}$ \\
\hline Media Hits (ln) & $\begin{array}{l}\text { Logarithm of the number of party mentions in stories about the EU; a value of } \\
1 \text { was added to the original number of mentions because the logarithm of } 0 \\
\text { is not defined }\end{array}$ \\
\hline $\begin{array}{l}\text { Media Consumption, } \\
\text { coded }\end{array}$ & $\begin{array}{l}\text { Maximum number of days spent viewing/reading one of the coded media } \\
\text { outlets that are used to calculate the number of media hits }(0-7)\end{array}$ \\
\hline $\begin{array}{l}\text { Media Consumption, } \\
\text { other }\end{array}$ & $\begin{array}{l}\text { Binary measure of consumption of media outlets not used to count the } \\
\text { number of media hits }(1=\text { yes })\end{array}$ \\
\hline $\begin{array}{l}\text { Propensity to Vote } \\
\text { (PTV) }\end{array}$ & $\begin{array}{l}\text { Probability to ever vote for the respective party; measured on a scale from } 0 \\
\text { (not at all probable) to } 10 \text { (very probable) }\end{array}$ \\
\hline Incumbency & $1=$ party is in national government; $0=$ otherwise \\
\hline European Identity & $\begin{array}{l}1=\text { respondent describes him/herself not just as a citizen of the respective } \\
\text { country but also or exclusively as a European; } 0=\text { otherwise }\end{array}$ \\
\hline Political Interest & $1=$ somewhat or very interested in politics; $0=$ otherwise \\
\hline Guesses & $\begin{array}{l}\text { Binary measure identifying respondents assigning the same value to all } \\
\text { parties in regard to their issue position }(1=\text { yes })\end{array}$ \\
\hline $\begin{array}{l}\text { Programmatic } \\
\text { Diversity }\end{array}$ & Standard deviation of verified party positions on EU integration by country \\
\hline $\begin{array}{l}\text { Effective Number of } \\
\text { Parties }\end{array}$ & Effective number of electoral parties \\
\hline
\end{tabular}

within-subject design, the lowest level (party level) is nested in the level of individuals (respondent level), and the latter is nested in the contextual level (country level). Therefore, the data structure resembles a stacked data matrix with a comparative framework that has been commonly used to analyse, for example, party choice. ${ }^{39}$

We do not restrict the sample to specific parties or just voters. However, the need to match four different datasets results in the loss of some cases, especially at the party level. Moreover, respondents drop out due to missing information on some of the control variables used. Still, our analysis covers 174 parties, 19,233 individuals and twenty-eight countries. ${ }^{40}$ The overall number of cases on the lowest level is 107,822 (which is equivalent to the sum of parties rated by all respondents in all countries). All models presented below are linear random intercept three-level models applying full maximum-likelihood estimation.

Even though perception gaps are quite large, does the availability of party news media and media consumption decrease those gaps? In order to examine these effects, we ran five different models: an intercept-only model (null model), two models for all media hits, one without (Model 1a) and one with interactions (Model 1b), and two models differentiating between quality and non-quality media hits (Models 2 and Model 3). ${ }^{41}$ The results are presented in Table 2. Based on the null model, we calculated the intra-class correlations (ICC) for both

39 van der Brug 2004.

${ }^{40}$ Due to the separation of the party and media system, we split Belgium into Flanders and Wallonia. Hence, we end up with twenty-eight, not twenty-seven, highest-level units. The fact that we refer to this level as the 'country level' is not a political statement.

${ }^{41}$ As shown in Figure 1, the number of media hits in quality and non-quality outlets is strongly correlated. Hence, we refrain from presenting a combined model with both the interaction of quality and non-quality hits and the respective consumption measures. Running such a combined model revealed the same pattern of effects. However, the effect size decreased, probably due to multicollinearity. 
higher levels. The ICC for the respondent level is 0.20 , which means that about one-fifth of the variation regarding the gap between verified and perceived party position is located between individuals. Only 5 per cent of the variation is located on the highest level (between countries). Hence, more than 70 per cent of the variation is within subjects (between parties). ${ }^{42}$

As is evident in Table 2, any given model is only able to explain a small amount of the dependent variable's variation. Based on the comparison of the error variance components of the explanatory models and the null model, the $\mathrm{R}^{2}$ values are always close to 0.05 . However, the models are rather parsimonious and a low $\mathrm{R}^{2}$ value is common when applying regression estimation to extremely large samples. Moreover, the $\mathrm{R}^{2}$ values are no indication as to whether the causal mechanisms regarding media effects have to be rejected or not.

As stated, we are also interested in the effect of media hits conditioned by media consumption on respondents' capacity to locate parties correctly on the issue of EU integration. Consequently, these variables are introduced as part of cross-level interactions in Models $1 \mathrm{~b}$, 2 and 3, making it rather unhelpful to interpret regression coefficients or significance levels as presented in Table 2. Instead, we interpret them on the basis of marginal effect plots.

Turning to the control variables first, we find a very stable pattern over all explanatory models. On the party level, both a higher propensity to vote (PTV) for a party and incumbency in the national arena decrease the perception gap significantly. The more likely it is for a respondent to vote for a party, the better is her knowledge of the party's policy position. This is good news for the link between electoral competition and meaningful choices: all other things equal, respondents know more about parties that they actually consider voting for. This is perfectly rational in a world of limited resources and, in particular, the low information environment surrounding second-order elections. Moreover, the position of parties in government is better known, which could be a direct consequence of policies - even on EU issues.

On the respondent level, individuals classified as guessing party positions produce unsurprisingly - larger gaps between verified and perceived positions, whereas the more politically interested and those identifying as European are more likely to correctly place parties. Consistent with past research, individual-level factors do a substantial job of explaining the variation in knowledge (in our case, party knowledge). It has to be noted, though, that we find much weaker effects of political interest in Models 2 and 3. In the latter, the coefficient is not significant.

On the country level, neither the diversity of party placements nor the effective number of electoral parties has a significant effect on the perception gap. Taking into account the rather low ICC on the country level, it is not surprising that country-level variables have no effect on the gap between perceived and verified party positions.

What do our results show about the effect of media hits and media consumption on the perception gap of party positions? One of our main variables of interest is the amount of information about a party in the media. The results of Model 1a are consistent with Hypothesis 1: the more information about a party - defined as media hits - available to a respondent, the better able she is to place the party. For the same individual, the more prominently a party features in the media, the smaller the gap between the verified position and the respondent's placement of that party. Put differently, given our within-subject design, for this same respondent, the gap, on average, widens when less information is available about another party. This main effect of media hits does not depend on the nature of the source: we get significant and negative coefficients regarding media hits in general as well as for media hits in quality and non-quality

\footnotetext{
42 The ICCs, as well as the log-likelihood reductions for all models presented in Table 2, speak strongly in favour of using the models in the way we specified them.
} 


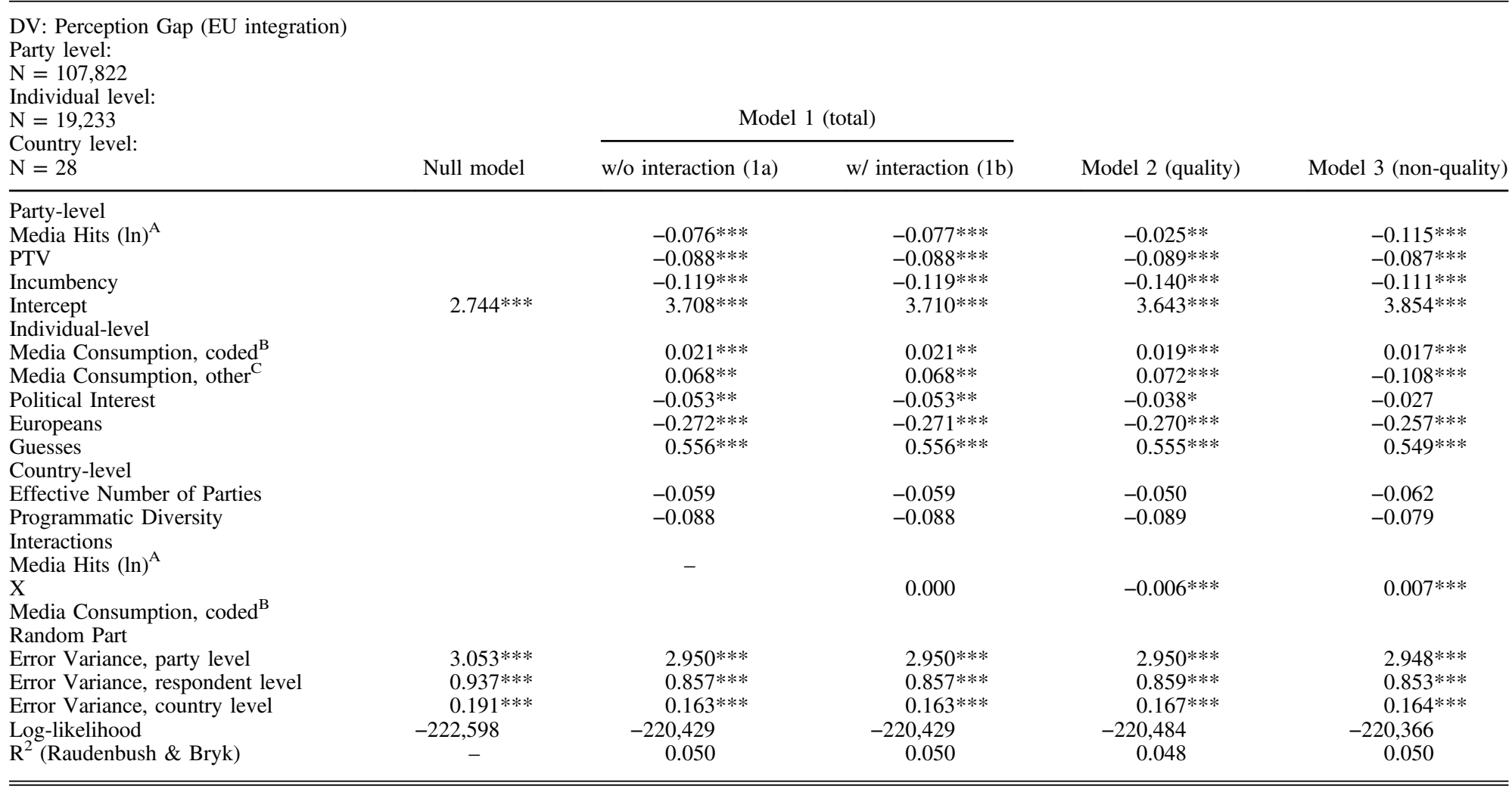

Notes: ${ }^{\mathrm{A}}$ Refers to all media hits in Models $1 \mathrm{a}$ and $1 \mathrm{~b}$, media hits in quality outlets in Model 2 and media hits in non-quality outlets in Model 3; ${ }^{\mathrm{B}}$ Refers to consumption of coded outlets in Models $1 \mathrm{a}$ and $1 \mathrm{~b}$, consumption of quality outlets in Model 2 and consumption of non-quality outlets in Model 3; ${ }^{\mathrm{C}}$ Refers to consumption of uncoded outlets in Models $1 \mathrm{a}$ and $1 \mathrm{~b}$, consumption of non-quality outlets in Model 2 and consumption of quality outlets in Model 3; *p $<0.05 ; * * \mathrm{p}<0.01 ; * * \mathrm{p}<0.001$ 
outlets (Models 2 and 3). ${ }^{43}$ The marginal effects plot on the lower-right corner of Figure 3 further supports this conclusion. ${ }^{44}$ Furthermore, the effect is, in absolute terms, larger for nonquality outlets. With regard to Hypotheses 3, we conclude that while both types of media hits decrease the perception gap, the information provided by non-quality outlets has a significantly larger effect, which might be due to the larger quantity of soft news.

Turning to media consumption for the coded content, Models 1a and $1 \mathrm{~b}$ measure the highest number of days per week on which any of the coded outlets is followed. For Models 2 and 3, we restrict the outlets considered to quality and non-quality outlets, respectively. For all models with interactions, media hits and consumption of coded outlets should be considered together: thus, we specified an interaction term capturing how consumption conditions the impact of party visibility in the media (see Hypothesis 2). In Model 1b, which does not distinguish between media outlets, the interaction term is not significant. However, when we look at Models 2 and 3 we find evidence for both Hypotheses 2 and 3: we see the differential impact of types of information and consumption. Quality information does not only reduce the gap, but given the negative coefficient for the interaction term, quality information reduces the gap even further the more respondents are exposed to it. Yet while information in non-quality outlets overall reduces the gap to the largest extent, the positive interaction term reveals that more frequent consumption of non-quality news reduces this effect: it narrows the gap such that higher levels of consumption of low-quality news have minimal effects on knowledge about party placements.

The marginal effects of a one-unit change in media hits for different levels of consumption are displayed in the upper plots as well as the lower-left plot of Figure 3. These effects provide information on significance levels conditioned on days of consumption and enable comparison between different numbers of days. The first graph displays an almost flat marginal effect: there is no change in the effect of media hits as consumption of all media increases. This would suggest that Hypothesis 2 cannot be confirmed. However, in the graphs differentiating between types of outlets, in the upper-right plot we see that as the consumption of quality news outlets increases, the gap between the verified party position and the respondent's placement decreases. In the lower-left graph on non-quality outlets, we see the opposite marginal effect: the impact of party visibility on reducing the gap between the respondent and the verified placement diminishes as consumption of non-quality news increases. Note that these effects are only significant if we compare no or low consumption to high levels of consumption. These results make it necessary to state Hypothesis 2 more precisely: the more often quality news is consumed, the better the ability to place a party correctly. However, this does not apply to nonquality news information, where we find a decreasing effect with higher levels of consumption. Hence, it is more about quality than quantity of information. This finding is further supported by the indicator on media consumption for non-coded outlets. As described above, we include a dummy variable indicating whether the respondent consumes other (uncoded) media outlets: these are non-quality outlets for respondents consuming quality outlets (Model 2) and quality outlets for respondents consuming non-quality outlets (Model 3). In Model 2, we find that such consumption increases the perception gap, while there is a negative coefficient in Model 3. In substantive terms, the consumption of non-quality outlets in addition to quality outlets makes it more difficult for respondents to locate parties, while it is the opposite for the additional consumption of quality outlets.

\footnotetext{
43 Due to space limitations, we refrain from presenting models without interactions for Models 2 and 3. However, the effect of media hits does not change significantly if we exclude the interactions.

${ }^{44}$ It is even more accurate because it measures the overall effect of media hits, which are a combination of the main effect and the interaction term.
} 


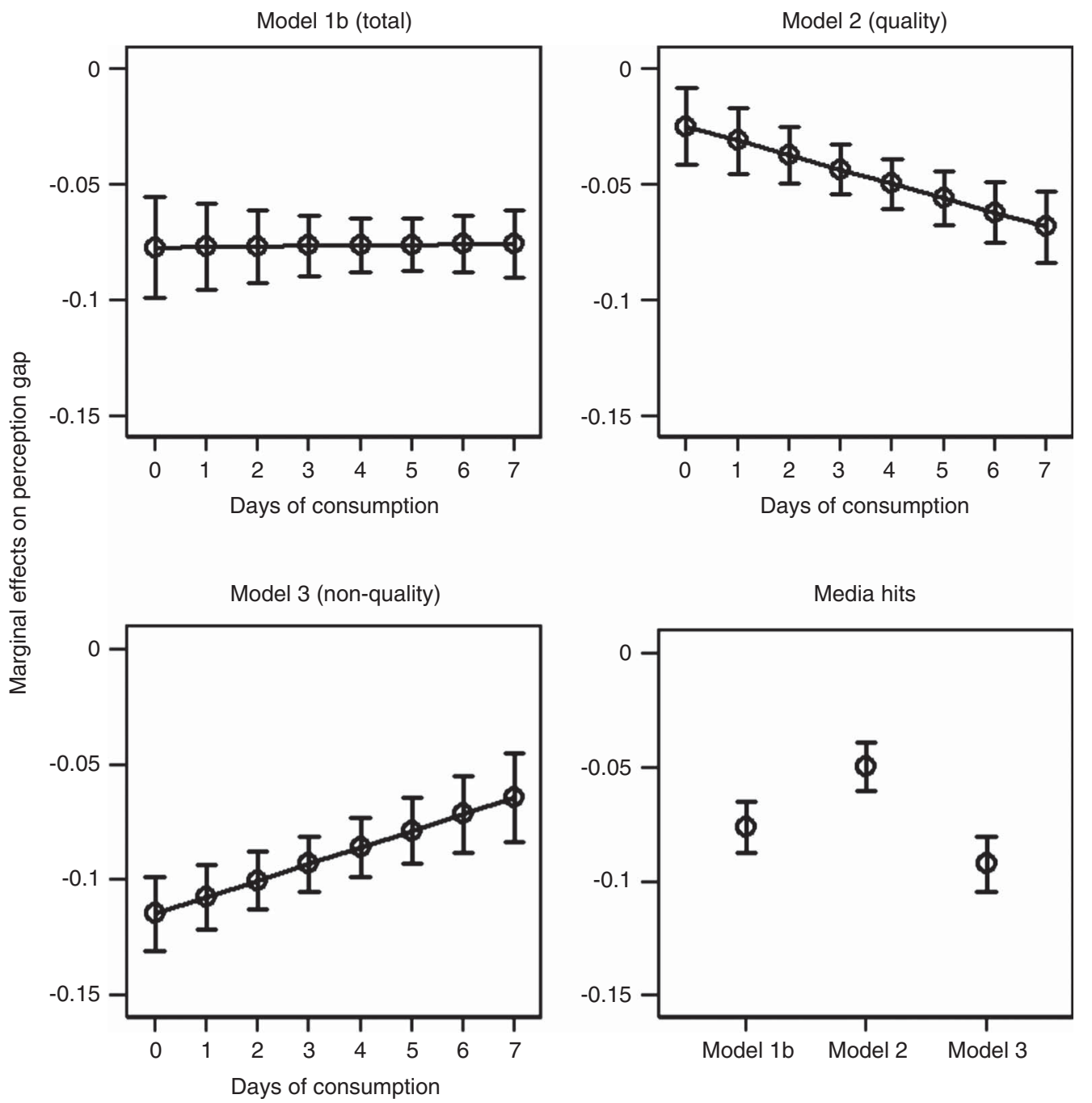

Fig. 3. Marginal effects of media hits and consumption on perception gap

Taking these findings together, we demonstrate a somewhat complicated picture that, nevertheless, seems to be a valid representation of prior studies on the differing effects of quality and non-quality outlets. The difference between the outlet types is much more prominent in regard to consumption patterns (Hypothesis 2), meaning that, all in all, the consumption of quality outlets decreases the perception gap to a larger degree than the consumption of nonquality outlets. Having said that, the information provided in non-quality outlets has a larger impact on the perception gap than its quality counterpart (Hypothesis 3).

\section{CONCLUSION}

The analysis we present has contributed to the scholarly debate on media effects on political knowledge. We have argued that where information is asymmetric about political parties, this 
has implications for models that use respondents' placement of parties in predicting vote choice. We have demonstrated that respondents are more likely to place parties closer to their verified position when more information is available. Our analysis shows that the news media play an important mediating role in supplying voters with this information. Our findings of a significant but small effect for the information environment reflect the complex array of factors that influences knowledge, but given the cumulative effect of news media information, these effects are supposed to exert an increasing, consistent influence in the long run. Furthermore, given the increasing number of news articles about the European integration project, ${ }^{45}$ and hence the increasing availability of EU news, we assume the effect will become stronger in the future.

As in other research where findings across types of outlets is not consistent, we find, on the one hand, that while available information reduces the perception gap in general, this effect is stronger for low-quality information. On the other hand, consumption of non-quality news and, by consequence, low-quality information - reduces the gap between verified and perceived positions, but the effect gets smaller the more often an individual reads non-quality press or watches non-quality news programmes. Hence, while we can observe an overall soft news effect for non-quality outlets, which provide easily accessible and new short messages, the more complex analytical news in quality outlets can unfold a stronger effect the more individuals are exposed to them.

Our analysis has also extended the use of a within-subject design to test media effects crossnationally. It allows us to arrive at more robust findings regarding the impact of information on knowledge about party positions. The design provides the possibility of testing how different levels of information about parties can lead to, within the same individual, different levels of knowledge about political parties. In this way, we have controlled for problems with selfselection and other confounding factors because they will be constant across individuals. This is a useful design, therefore, when using observational data.

Turning to the issue of European integration, a number of studies show that when the EU is more visible in the news or salient in a country, voters give greater weight to the distance they have from the government party on the EU dimension. ${ }^{46}$ Our findings suggest that the actual distance a voter may perceive herself from a party is endogenous to the information environment because it provides - to a varying degree - resources to locate parties correctly. More knowledgeable, and hence reliable, EU issue distances are produced for more visible parties. Therefore, that party positions are more salient when there is more information may be an effect of learning rather than EU issue priming. ${ }^{47}$ As information is not equally available for all parties, this effect varies, and parties' EU issue positions will impact vote choice models differently. In other words, the utility of voting for a certain party with regards to the issue of EU integration varies due to the amount of available information and the source's quality.

How can these results be generalized? Given the fact that parties and the news media put greater emphasis on issues that are already available in their electoral campaigns, the knowledge gains should be even larger in contexts with longer and more intense campaigns compared to the European Parliament elections. ${ }^{48}$ This applies to both general elections and issue dimensions such as the left-right dimension. Overall, knowing more is not just a desirable goal; it also makes voters less likely to feel disappointed with their vote choice during the election period.

45 Boomgaarden et al. 2013.

46 de Vries 2007, 2010; Hobolt, Spoon, and Tilley 2009.

47 de Vries 2010.

${ }^{48}$ Hansen and Pedersen 2014. 


\section{REFERENCES}

Aalberg, Toril, Peter van Aelst, and James Curran. 2010. Media Systems and the Political Information Environment: A Cross-National Comparison. The International Journal of Press/Politics 15:255-71.

Aarts, Kees, and Holli Semetko. 2003. The Divided Electorate: Media Use and Political Involvement. The Journal of Politics 65:759-84.

Alvarez, R. Michael, and Charles H. Franklin. 1994. Uncertainty and Political Perceptions. The Journal of Politics 56:671-88.

Ansolabehere, Stephen, and Shanto Iyengar. 1995. Going Negative: How Attack Ads Shrink and Polarize the Electorate. New York: Free Press.

Bakker, Ryan, Catherine de Vries, Erica Edwards, Liesbet Hooghe, Seth Jolly, Gary Marks, Jonathan Polk, Jan Rovny, Marco Steenbergen, and Milada Anna Vachudova. 2015. Measuring Party Positions in Europe: The Chapel Hill Expert Survey Trend File, 1999-2010. Party Politics 21:143-52.

Barabas, Jason, and Jennifer Jerit. 2009. Estimating the Causal Effects of Media Coverage on PolicySpecific Knowledge. American Journal of Political Science 53:73-89.

Baum, Matthew A. 2003. Soft News and Political Knowledge: Evidence of Absence or Absence of Evidence? Political Communication 20:173-90.

Boomgaarden, Hajo G., Claes H. de Vreese, Andreas R.T. Schuck, Rachid Azrout, Matthijs Elenbaas, Joost H.P. van Spanje, and Rens Vliegenthart. 2013. Across Time and Space: Explaining Variation in News Coverage of the European Union. European Journal of Political Research 52:608-29.

Braun, Daniela, Slava Mikhaylov, and Hermann Schmitt. 2010. European Parliament Election Study 2009, Manifesto Study, GESIS Data Archive, Cologne, ZA5057 Data file Version 1.0.0.

Brewer, Paul R., and Xiaoxia Cao. 2006. Candidate Appearances on Soft News Shows and Public Knowledge About Primary Campaigns. Journal of Broadcasting \& Electronic Media 50:18-35.

Chan, Jimmy, and Wing Suen. 2009. Media as Watchdogs: The Role of News Media in Electoral Competition. European Economic Review 53:799-814.

Curran, James, Shanto Iyengar, Anker Brink Lund, and Inka Salovaara-Moring. 2009. Media System, Public Knowledge and Democracy: A Comparative Study. European Journal of Communication 24:5-26.

Delli Carpini, Michael X., Fay Lomax Cook, and Lawrence R. Jacobs. 2004. Public Deliberation, Discursive Participation, and Citizen Engagement: A Review of the Empirical Literature. Annual Review Political Science 7:315-44.

Delli Carpini, Michael X., and Scott Keeter. 1996. What Americans Know About Politics and Why It Matters. New Haven, CT: Yale University Press.

de Vreese, Claes, Susan A. Banducci, Holli Semetko, and Hajo Boomgarden. 2006. The News Coverage of the 2004 European Parliamentary Election Campaign in 25 Countries. European Union Politics 7:479-506.

de Vries, Catherine. 2007. Sleeping Giant: Fact or Fairytale? How European Integration Affects Vote Choice in National Elections. European Union Politics 8:363-85.

—. 2010. EU Issue Voting: Asset or Liability? How European Integration Affects Parties' Electoral Fortunes. European Union Politics 11:89-117.

Dimock, Michael, and Samuel Popkin. 1997. Political Knowledge in Comparative Perspective. In Do the Media Govern?, edited by Shanto Iyengar and Richard Reeves, 217-24. Thousand Oaks, CA: Sage.

Downs, Anthony. 1957. An Economic Theory of Democracy. New York: Harper and Row.

Gelman, Andrew, and Gary King. 1993. Why Are American Presidential Election Campaign Polls so Variable When Votes are so Predictable? British Journal of Political Science 23:409-51.

Giebler, Heiko, and Bernhard Weßels. 2010. 2009 European Election Candidate Study - Methodological Annex. Berlin: WZB.

Giebler, Heiko, Elmar Haus, and Bernhard Weßels. 2010. 2009 European Election Candidate Study Codebook. Berlin: WZB.

Hansen, Kasper M., and Rasmus Tue Pedersen. 2014. Campaign Matter: How Voters Become Knowledgeable and Efficacious During Election Campaigns. Political Communication 31:302-24. 
Hobolt, Sara B., Jae-Jae Spoon, and James Tilley. 2009. A Vote Against Europe? Explaining Defection at the 1999 and 2004 European Parliament Elections. British Journal of Political Science 39:93-115.

Jerit, Jennifer, Jason Barabas, and Toby Bolsen. 2006. Citizens, Knowledge, and the Information Environment. American Journal of Political Science 50:266-82.

Koch, Jeffrey W. 2008. Campaign Advertisements' Impact on Voter Certainty and Knowledge of House Candidates' Ideological Positions. Political Research Quarterly 61:609-21.

Lecheler, Sophie, and Claes H. de Vreese. 2013. What a Difference a Day Makes? The Effects of Repetitive and Competitive News Framing Over Time. Communication Research 40:147-75.

Lenz, Gabriel. 2012. Follow the Leader? How Voters Respond to Politicians' Policies and Performances. Chicago, IL: University of Chicago Press.

Macdonald, Stuart Elaine, George Rabinowitz, and Ola Listhaug. 1998. On Attempting to Rehabilitate the Proximity Model: Sometimes the Patient Just Can't Be Helped. Journal of Politics 60:653-90.

Mendelsohn, Matthew. 1996. The Media and Interpersonal Communications: The Priming of Issues, Leaders, and Party Identification. Journal of Politics 58:112-25.

Mendelsohn, Matthew, and Fred Cutler. 2000. The Effect of Referendums on Democratic Citizens: Information, Politicization, Efficacy and Tolerance. British Journal of Political Science 30:685-98.

Paik, Haejung, and George Comstock. 1994. The Effects of Television Violence on Antisocial Behavior: A Meta-Analysis. Communication Research 21:516-46.

Peter, Jochen, Edmund Lauf, and Holli A. Semetko. 2004. Television Coverage of the 1999 European Parliamentary Elections. Political Communication 21:415-33.

Preiss, Raymond W., Barbara M. Gayle, Nancy Burrell, Mike Allen, and Jennings Bryant, eds. 2007. Mass Media Effects Research: Advances Through Meta-Analysis. New York: Routledge.

Prior, Markus. 2003. Any Good News in Soft News? The Impact of Soft News Preferences on Political Knowledge. Political Communication 20:149-71.

2009. The Immensely Inflated News Audience: Assessing Bias in Self-Reported News Exposure. Public Opinion Quarterly 73:130-43.

Rabinowitz, George, and Stuart Elaine Macdonald. 1989. A Directional Theory of Issue Voting. American Political Science Review 83:93-121.

Reinemann, Carsten, James Stanyer, Sebastian Scherr, and Guido Legnante. 2011. Hard and Soft News: A Review of Concepts, Operationalizations and Key Findings. Journalism 13:221-39.

Rovny, Jan. 2012. Who Emphasizes and Who Blurs? Party Strategies in Multidimensional Competition. European Union Politics 13:269-92.

Schuck, Andreas, Georgios Xezonakis, Susan Banducci, and Clase H. de Vreese. 2010. European Parliament Election Study 2009, Media Study, GESIS Data Archive, Cologne, ZA5056 Data file Version 1.0.0.

Schuck, Andreas R.T., Georgios Xezonakis, Matthijs Elenbaas, Susan A. Banducci, and Claes H. de Vreese. 2011. Party Contestation and Europe on the News Agenda: The 2009 European Parliamentary Elections. Electoral Studies 30:41-52.

Sekhon, Jasjeet S., and Rocio Titiunik. 2012. When Natural Experiments are Neither Natural nor Experiments. American Political Science Review 106:35-57.

Shepsle, Kenneth. 1972. The Strategy of Ambiguity: Uncertainty and Electoral Competition. American Political Science Review 66:555-69.

Soroka, Stuart, Blake Andrew, Toril Aalberg, Shanto Iyengar, James Curran, Sharon Coen, Kaori Hayashi, Paul Jones, Gianpietro Mazzoleni, June Woong Rhee, David Rowe, and Rod Tiffen. 2013. Auntie Knows Best? Public Broadcasters and Current Affairs Knowledge. British Journal of Political Science 43:719-39.

Stevens, Daniel P. 2008. Measuring Exposure to Political Advertising in Surveys. Political Behavior 30:47-72.

Swanson, David L., and Paolo Mancini, eds. 1996. Politics, Media, and Modern Democracy: An International Study of Innovations in Electoral Campaigning and Their Consequences. Westport, CT: Praeger.

van der Brug, Wouter. 2004. Issue Ownership and Party Choice. Electoral Studies 23:209-33. 
van der Eijk, Cees, and Mark N. Franklin. 2004. Potential for Contestation on European Matters at National Elections in Europe. In European Integration and Political Conflict, edited by Gary Marks and Marco R. Steenbergen, 33-50. Cambridge: Cambridge University Press.

van Egmond, Marcel, Wouter van der Brug, Sara B. Hobolt, Mark Franklin, and Eliyahu V. Sapir. 2013. European Parliament Election Study 2009, Voter Study, GESIS Datenarchiv, Köln, ZA5055 Data file Version 1.1.0.

Weßels, Bernhard. 2011. European Parliament Election Study 2009, Candidate Study, GESIS Data Archive, Cologne, ZA5048 Data file Version 2.0.0.

Westholm, Anders. 1997. Distance Versus Direction: The Illusionary Defeat of the Proximity Theory of Electoral Choice. American Political Science Review 91:865-83.

Zaller, John. 1999. A Theory of Media Politics: How the Interests of Politicians, Journalists, and Citizens Shape the News. Unpublished manuscript. Available from http://www.sscnet.ucla.edu/polisci/ faculty/zaller/media\%20politics\%20book\%20.pdf, accessed 13 March 2014.

2002. The Statistical Power of Election Studies to Detect Media Exposure Effects in Political Campaigns. Electoral Studies 21:297-329. 